\title{
Job Challenges Faced by Novice EFL High School Teachers
}

\author{
Ngoc Duyen Tran ${ }^{1}$ \\ ${ }^{1}$ School of Foreign Languages, Can Tho University, Vietnam
}

\begin{abstract}
The transition from pre-service teachers into novice teachers is a challenging process that has certain effects on teachers' lifelong careers. This study was conducted with the aim of exploring the job challenges that novice EFL high school teachers in the Mekong Delta of Vietnam faced in their first five years of teaching practice. This descriptive study adopted two research tools, including questionnaire and semi-structured interview. Thirty novice EFL high school teachers responded to the questionnaire and four of them were invited to participate in a semi-structured interview. The results showed that novice EFL high school teachers encountered job challenges at a medium frequency level. Specifically, based on the results of three One-Sample T Tests, it can be concluded that the novices were confronted with school context challenges at a high level, followed by the medium level of learners and classroom management challenges. Novices just dealt with lesson-related challenges at a low level. In addition, the findings from the semi-structured interviews presented several different job challenges including applying the teaching methods learned at university, lesson preparation, students' negative attitudes towards learning English, students' proficiency, workload, and pressure of achievement or credit-driven practice. Future studies on novice EFL teachers' job challenges should be done on a larger scale and scope, and employ multiple research methods to collect the data.
\end{abstract}

Keywords - job challenges, EFL, novice teachers, high school

\section{INTRODUCTION}

Every year, a large number of pedagogical students graduating from colleges and universities begin to engage in teaching. The early years of teaching are believed to play a crucial role in a teacher's career. Pitton (2006) confirmed that there is a close connection of new teachers' success to what they experience, and the opportunities they receive to express their classroom difficulties in the early years of the profession. However, the transition from pre-service training programs to teaching is often a dramatic and painful experience for novice teachers (Senom, Zakaria \& Ahmad Shah, 2013). Right after admission into the job, novice teachers are allocated similar tasks as their more experienced colleagues. Yost (2006) stated that the most difficult teaching tasks are often assigned to novice teachers and they are expected to be as well-performed as experienced ones. Fantilli and McDougall (2009) found that novice teachers often find their jobs frustrating, unrewarding and challenging to deal with. The challenges, especially job challenges that novice teachers face, could result in an increase in the attrition rate. According to Ozturk (2008), between 25\% and 50\% of new teachers quit their jobs in the first three years of teaching. To Hong (2010), a large number of novice teachers leave their jobs during the first five years of their teaching careers. The question that needs to be answered is what job difficulties novice teachers are facing. Many recent studies have examined the difficulties faced by early-career English teachers in general and on job difficulties in particular. However, the number of studies focusing on job challenges faced by Vietnamese novice EFL high school teachers is still rare, to the best knowledge of the researcher of this study. Hence, this study aims to explore the job challenges that novice EFL high school teachers in the Mekong Delta of Vietnam face in their first five years of teaching. The study is guided by the research question "What job challenges do novice EFL high school teachers face in their first five years teaching in high schools?".

\section{LITERATURE REVIEW}

In the available literature, novice teachers were mentioned with various names such as new, newly qualified, newly recruited, beginning, or early career teachers. Farrell (2012) suggested that there was no precise definition of a novice teacher in literature. Additionally, there was no universal agreement on how long the period of teaching is required to complete the novice stage. For the purpose and scope of this study, a novice teacher was identified as a teacher with five years of teaching experience or fewer. Regarding teaching time, the novices belonged to four groups which were first-year, second and third-year, third and fourth-year, and fifth-year. The 
DOI: $\underline{10.51386 / 25815946 / \mathrm{ijsms}-\mathrm{v} 4 \mathrm{i} 5 \mathrm{p} 109}$

Volume: 4 Issue: 5

September to October 2021

https://www.ijsmsjournal.org

participants' years of teaching experiences were divided based on the model of two scholars, Dreyfus and Dreyfus (Dreyfus and Dreyfus, 1986, as cited in Villegas-Reimers, 2003).

In the following paragraphs, selected studies on job challenges faced by novice EFL teachers were reviewed from past to present.

Korukçu (1996) conducted a study on pre-service and beginning EFL teachers to figure out the problems they encountered in the Department of Basic English in Turkish universities. The findings indicated the most troublesome areas for the participants which were teaching methodologies, classroom management, lesson designing, and learners' motivation.

In addition, heavy workload of teaching and non-teaching issues, teaching in large class sizes, low proficient learner, and dealing with misbehaved learners were the main challenges found by Richards and Pennington (1998) in their study of five novice ESL teachers working at secondary schools in Hong Kong.

In the context of Turkey, Akcan (2016) executed a study to explore fifty-five novice EFL teachers' challenges by using surveys and interviews. The findings reported that the main challenges during their initial years of teaching were delivering lessons, behaviour management, non-motivated pupils and disabled pupils in learning.

Alhamad (2018) conducted a study to examine the problems faced by novice EFL teachers in Saudi Arabia when they were entering their first teaching positions. The findings showed that tackling low English skill students and students' unfavorable attitudes towards learning English were the most visible obstacles mentioned by the studying participants. This research has also identified other noticeable challenges such as the adoption of different educational techniques and student-centered focus, management of student behaviour, course planning, and addressing individual differences.

Sali and Kecik (2018) investigated the challenges faced by seven novice EFL teachers in primary and secondary schools in Turkey. Regarding job challenges, various issues were found. First, problems in classroom management included providing and maintaining classroom discipline, planning instruction and lessons management. Besides, problems in foreign language teaching and learning consisted of low English proficiency learner, poor motivation and interest, utilizing language teaching techniques and sources, language skills teaching, being incapable of adding variety to classes, teacher knowledge of language and teaching, addressing individual learner differences, putting theory into practice, and lack of language teaching course books. Finally, difficulties in school context were made up of large classes, insufficient materials/appliances for schools, severe teaching burdens, underprivileged learners and allocation of time for English in the curriculum.

Belatrech (2018) undertook a study to investigate challenges on 14 novice EFL teachers in middle and secondary schools at Mostaganem rural areas, Algeria. The results showed that certain initial EFL teachers confronted several problems. The job difficulties they faced included classroom management difficulties, and pedagogical difficulties namely lesson planning, adapting lessons to suit pupils' levels and ICT tools' usage.

Widiati, Suryati and Hayati (2018) conducted a qualitative case study to examine the challenges of eleven English teachers at secondary schools (junior and senior high schools and vocational schools) in Malang areas, Indonesia. The results of the study revealed different problems for the new teachers consisting of lesson planning and implementation according to the 2013 Curriculum, learners' motivation and evaluation procedures that are applicable to a relatively low-capacity group of students and management of a large classroom.

In Indonesia, Mahmud (2020) explored the challenges faced by early-career teachers during their first years teaching at school after completing the PPG program [PPG program: the post-bachelor teacher professional education program or Pendidikan Profesi Guru (PPG) for both pre-service and in-service EFL teachers in 2013]. In terms of job challenges, this study has shown that early-career teachers faced pedagogical challenges including classroom control, inadequate teaching resources, and learning environment centered on testing.

Lately, Lomi and Mbato (2020) conducted a qualitative study on three novice EFL teachers in order to investigate the struggles in their first year of teaching. Job problems were linked to classroom management, students' capacities and attitudes, and lack of school resources and facilities.

This section provided the concepts of novice teachers and the related literature including challenges faced by (EFL/ESL) novice teachers. From the review, numerous types of job challenges were found which can be divided into three clusters namely lesson-related challenges, learners and classroom management challenges, 
DOI: $\underline{10.51386 / 25815946 / \mathrm{ijsms}-\mathrm{v} 4 \mathrm{i} 5 \mathrm{p} 109}$

Volume: 4 Issue: 5

September to October 2021

https://www.ijsmsjournal.org

and school context challenges. For example, challenges like applying teaching methods and lesson preparation could be grouped into the cluster of lesson-related challenges. Among the studies conducted on novice EFL teachers' job challenges in the beginning phase, studies in the context of Vietnam are considered scarce. Therefore, it is necessary to conduct the current study to bridge the gap. When the job challenges novice EFL teachers face are understood, necessary adjustments or solutions could be made to better scaffold them to smoothly overcome this transition stage.

\section{RESEARCH METHODOLOGY}

This study was designed as descriptive, cross-sectional research in which a mixed-method approach was employed. According to Tashakkori and Teddlie (1998), the application of a mixed-method brought value to the research findings of the study in a way that could not be done by one kind of data only. There were two stages. Firstly, a five-point Likert questionnaire was adopted as a tool for collecting quantitative data, with the aim of exploring the job challenges facing novice EFL high school teachers during their beginning phases. Then, a semi-structured interview to collect qualitative data was employed to gain insights into the novices' job challenges. The semi-structured interview was recorded with interviewees' consent for later transcription. In addition, participants' information was kept confidential. The language used in the semi-structured interview was Vietnamese to ensure that the data was accurate and clear. Later on, the researcher transcripted that data. The interview took place online due to the spread of the Covid 19 pandemic.

From the results of related studies, a questionnaire was synthesized and designed by the researcher. Questionnaires offer the researcher more standard information and decrease the probable impact of the researcher's presence on participant responses (Bryman, 2008). Specifically, except for items aggregated and developed based on the literature review, most of the items in the questionnaire were adopted and adapted from two questionnaires in the study by Öztürk and Yildirim (2013), and Alhamad (2018) who conducted research on novice teachers' adaptation challenges during the beginning phase, and on challenges and needs of Saudi Arabian EFL novice teachers respectively. The questionnaire included 18 items in total which aimed at investigating the job challenges novice EFL high school teachers faced in their first five years of teaching practice. The questionnaire included four main sections. The first section required basic personal information, consisting of gender, years of teaching at high school and high school locations. Section two consisting of seven items belonged to lesson-related challenges (items 1, 2, 3, 4, 5, 6, 7). Section three consisted of seven items with the purpose of collecting data on learners and classroom management challenges (items 8, 9, 10, 11, 12, 13, 14). Section four included four items designed to investigate school context challenges (items 15, 16, 17, 18).

The Vietnamese questionnaire was piloted on twelve novice teachers. Those twelve novice teachers were encouraged to indicate which questionnaire items were ambiguous and had comments on the questionnaire if all items belonging to the suitable cluster. Later, participants were invited to answer the official questionnaire on Messenger. All quantitative data were subjected to SPSS version 22 for statistical analysis.

Based on the contents of the questionnaire, the questions in the semi-structured interview was raised. Four participants volunteered to answer the interviews. The questions included in the semi-structured interview were sent to participants one week before the official interview took place. Due to the outbreak of Covid 19 at the present and the dispersion in the workplace of participants, four interviews were conducted online via Facebook Messenger at participants' conveniences and preferences. All interviews were recorded by a smartphone. All recorded audios were transcribed in Vietnamese and read carefully. In the next step, the data was coded into themes regarding lesson-related challenges, learners and classroom management challenges, and school context challenges. Pseudonyms were used to protect participants' identity confidentiality.

After constructing and piloting the questionnaire, it was delivered to the convenient sampling of thirty participants, who volunteered to answer the questionnaire. The criteria for participants' selection was that they must be EFL teachers teaching at public high schools with one to five years of experience. They all had a degree majoring in English teacher education and were working in provinces in the Mekong Delta, Vietnam. After thirty participants responded to the questionnaire, four novice EFL high school teachers, who were willing to leave their contacts, were invited to take part in the interview. Four interviewees had different levels of experience. Two are male, and two are female. 
DOI: $\underline{10.51386 / 25815946 / \mathrm{ijsms}-\mathrm{v} 4 \mathrm{i} 5 \mathrm{p} 109}$

Volume: 4 Issue: 5

September to October 2021

https://www.ijsmsjournal.org

\section{FINDINGS}

This section reports the results of the current study. It devotes to job challenges novice EFL high school teachers faced in their first five years of teaching practice.

\section{A. The Job Challenges Found From Quantitative Data}

An eighteen-item questionnaire was delivered to thirty participants to collect data related to job challenges. This main issue was divided into three clusters which were lesson-related challenges, learners and classroom management challenges, and school context challenges. A Scale Test was computed to check the reliability of eighteen items in the questionnaire. The results are shown in Table I.

TABLE I

THE RELIABILITY OF THE QUESTIONNAIRE

\begin{tabular}{|c|c|c|c|}
\hline Questionnaire & Number of respondents & Cronbach's Alpha & N of Items \\
\hline Job challenges & 30 & 0.89 & 18 \\
\hline
\end{tabular}

The result indicated that the Cronbach's Alpha of job challenges in the questionnaire was 0.89. Therefore, the questionnaire was reliable enough to be used to collect data in this current study.

As mentioned above, eighteen items were used to measure the novices' job challenges. A Descriptive Statistics Test was computed to examine its mean score. The result was presented in Table II.

TABLE II DESCRIPTIVE STATISTICS ON JOB CHALLENGES

\begin{tabular}{|c|c|c|c|c|c|}
\hline & $\mathrm{N}$ & Minimum & Maximum & Mean & Std. Deviation \\
\hline Job challenges & 30 & 2.11 & 4.50 & 3.01 & .63 \\
\hline
\end{tabular}

A One-Sample $\mathrm{T}$ Test was run to test whether the mean score of job challenges $(\mathrm{M}=3.01)$ is statistically different from the test value of 3.6, the starting point of the high level in the scale of Oxford (1990) presented in Table III. The result indicates that there is a great difference between the mean score of 3.01 and the test value of $3.6(\mathrm{t}=-5.07, \mathrm{df}=29, \mathrm{p}=.00)$. It can be concluded that the novices faced job challenges at a medium level.

TABLE III KEY TO UNDERSTANDING THE AVERAGES (OXFORD, 1990)

\begin{tabular}{|l|c|}
\hline \multicolumn{1}{|c|}{ Level } & Range \\
\hline Very high & 4.5 to 5.0 \\
\hline High & 3.6 to 4.4 \\
\hline Medium & 2.5 to 3.5 \\
\hline Low & 1.0 to 2.4 \\
\hline
\end{tabular}

Three Descriptive Statistics Tests were calculated to measure the mean scores of three clusters of job challenges. Table IV displays the results of the test.

TABLE IV

DESCRIPTIVE STATISTICS OF THE THREE CLUSTERS OF JOB CHALLENGES

\begin{tabular}{|l|l|l|l|l|c|}
\hline Clusters & N & Min & Max & Mean & SD \\
\hline Lesson-related Challenges & 30 & 1.43 & 4.29 & 2.67 & .73 \\
\hline $\begin{array}{l}\text { Learners and classroom Management } \\
\text { challenges }\end{array}$ & 30 & 2.00 & 4.86 & 3.18 & .78 \\
\hline School context challenges & 30 & 1.75 & 4.25 & 3.33 & .74 \\
\hline
\end{tabular}

A One-Sample $\mathrm{T}$ Test was run on lesson-related challenges to investigate whether its mean score $(\mathrm{M}=2.67$, $\mathrm{SD}=.73$ ) is statistically different from the test value of 2.4 , which is a low level in the scale used in this study. The result showed that no significant difference between the mean score $(M=2.67, \mathrm{SD}=.73)$ and the test value of 2.4 can be observed $(\mathrm{t}=2.01, \mathrm{df}=29, \mathrm{p}=.054)$. The results supported the conclusion that the novices deal with lesson-related challenges at a low level. 
DOI: $\underline{10.51386 / 25815946 / \mathrm{ijsms}-\mathrm{v} 4 \mathrm{i} 5 \mathrm{p} 109}$

Volume: 4 Issue: 5

September to October 2021

https://www.ijsmsjournal.org

Another One-Sample T Test was conducted to figure out whether the mean score of learners and classroom management challenges $(\mathrm{M}=3.18, \mathrm{SD}=.78)$ statistically differed from the test value of 3.6, which is the acceptable mean for a high level of frequency. The result showed that a significant difference between the mean score $(\mathrm{M}=3.18, \mathrm{SD}=.78)$ and the test value of 3.6 was observed $(\mathrm{t}=-2.94, \mathrm{df}=29, \mathrm{p}=.01)$, which means the novices' level of learners and classroom management challenges was medium.

Another One-Sample T Test was also computed to evaluate whether the mean score of school context challenges is statistically different from the test value of 3.6, the lowest limit of high level in the scale. The result indicated that no difference between the mean score $(\mathrm{M}=3.33, \mathrm{SD}=.74)$ and the test value of 3.6 was observed ( $\mathrm{t}=-2.04, \mathrm{df}=29, \mathrm{p}=.051)$. Therefore, the mean score of the novices' school context challenges was at a high level.

Another Descriptive Statistic Test was computed on eighteen items to find out the items gained the highest and lowest mean scores of frequency. The results are displayed in Table V.

TABLE V

DESCRIPTIVE STATISTICS

\begin{tabular}{|c|c|c|c|c|c|}
\hline & $\mathbf{N}$ & Min & Max & Mean & SD \\
\hline \multicolumn{6}{|l|}{ I. Lesson-related Challenges } \\
\hline Q1: I have difficulty in planning my lessons. & 30 & 1.00 & 4.00 & 2.57 & .86 \\
\hline Q2: I have difficulty in implementing my lessons. & 30 & 1.00 & 4.00 & 2.43 & .86 \\
\hline Q3: I have difficulty in choosing appropriate teaching methods. & 30 & 1.00 & 5.00 & 2.77 & 1.04 \\
\hline Q4: I have difficulty in testing and evaluation. & 30 & 1.00 & 5.00 & 2.47 & 1.17 \\
\hline $\begin{array}{l}\text { Q5: I feel that my knowledge of the English language, my } \\
\text { knowledge of teaching English, and my ability to use the English } \\
\text { language to teach are limited. }\end{array}$ & 30 & 1.00 & 5.00 & 2.77 & 1.17 \\
\hline $\begin{array}{l}\text { Q6: I have difficulty with the time allocated to English subject in } \\
\text { the curriculum. }\end{array}$ & 30 & 1.00 & 5.00 & 3.30 & 1.12 \\
\hline Q7: I have difficulty in using ICT tools in my classes. & 30 & 1.00 & 5.00 & 2.37 & 1.10 \\
\hline \multicolumn{6}{|l|}{ II. Learners and Classroom Management Challenges } \\
\hline $\begin{array}{l}\text { Q8: I have difficulty in managing my students' negative attitudes } \\
\text { toward learning English. }\end{array}$ & 30 & 2.00 & 5.00 & 3.40 & 1.13 \\
\hline $\begin{array}{l}\text { Q9: I have difficulty with the lack of students' motivation and } \\
\text { interest to learn English. }\end{array}$ & 30 & 2.00 & 5.00 & 3.40 & .89 \\
\hline Q10: I have difficulty in managing students' behaviors. & 30 & 1.00 & 5.00 & 3.20 & 1.16 \\
\hline Q11: I have difficulty in establishing student-centered approach. & 30 & 2.00 & 5.00 & 2.80 & 1.00 \\
\hline $\begin{array}{l}\text { Q12: I have difficulty in dealing with low English proficiency } \\
\text { students. }\end{array}$ & 30 & 2.00 & 5.00 & 3.17 & 1.12 \\
\hline Q13: I have difficulty in teaching at mixed-level classes. & 30 & 2.00 & 5.00 & 3.60 & .97 \\
\hline Q14: I have difficulty in classroom management. & 30 & 2.00 & 5.00 & 2.70 & 1.02 \\
\hline \multicolumn{6}{|l|}{ III. School Context Challenges } \\
\hline Q15: I have challenges in my workload. & 30 & 1.00 & 5.00 & 3.77 & 1.10 \\
\hline $\begin{array}{l}\text { Q16: I have challenges with the lack of school facilities and } \\
\text { teaching resources. }\end{array}$ & 30 & 1.00 & 5.00 & 3.40 & 1.25 \\
\hline Q17: I have difficulty in teaching in large class sizes. & 30 & 1.00 & 5.00 & 3.40 & 1.10 \\
\hline $\begin{array}{l}\text { Q18: I am unable to connect my undergraduate training with the } \\
\text { current atmosphere of the school. }\end{array}$ & 30 & 1.00 & 5.00 & 2.73 & 1.11 \\
\hline
\end{tabular}

From Table V, it can be seen that the two statements having the highest mean scores of frequency were related to workload $(\mathrm{M}=3.77, \mathrm{SD}=1.1)$ and teaching at mixed-level classes $(\mathrm{M}=3.6, \mathrm{SD}=0.97)$. These two means belong to the high level in the adopted scale (Oxford, 1990). It could be concluded that the burden of workload and teaching at classes where students had different levels of proficiency were the two most troublesome issues to novice teachers. Interestingly, in the medium range, there were four statements having the same highest mean score. The four statements were regarding to students' negative attitudes $(\mathrm{M}=3.4, \mathrm{SD}=1.13)$, students' motivation and interest $(\mathrm{M}=3.4, \mathrm{SD}=0.89)$, school facilities and teaching resources $(\mathrm{M}=3.4, \mathrm{SD}=1.25)$, and large class sizes $(\mathrm{M}=3.4, \mathrm{SD}=1.1)$. Furthermore, two statements receiving the lowest mean scores are in connection 
DOI: $\underline{10.51386 / 25815946 / \mathrm{ijsms}-\mathrm{v} 4 \mathrm{i} 5 \mathrm{p} 109}$

Volume: 4 Issue: 5

September to October 2021

https://www.ijsmsjournal.org

with implementing the lessons $(\mathrm{M}=2.43, \mathrm{SD}=0.86)$ and using ICT tools $(\mathrm{M}=2.37, \mathrm{SD}=1.1)$. It could be explained that novice teachers had very few challenges in carrying out the lessons or applying ICT tools into their lessons.

\section{B. The Challenges Found From Qualitative Data}

From the semi-structured interview, it was found that novice EFL high school teachers faced several job challenges related to applying the teaching methods learned at university, lesson preparation, students' negative attitude towards learning English, students' proficiency, workload, and the pressure of achievement or creditdriven practice. These challenges are categorized into three clusters like in the questionnaire namely lessonrelated challenges, learners and classroom management challenges, and school context challenges.

\section{Lesson-related Challenges}

Challenges in applying the teaching methods learned at university: All four participants reported that they had difficulties applying the teaching methods they had learned at university. The excerpts below provided more details about their views.

"When I use it [teaching methods] in my work, oh my god it's different" (Thanh, line 270)

“...I study 10 parts, but I can only apply about one, two or three parts...” (Nam, line 422-423)

"The methods are applicable but it will be difficult on the issue of the student's level” (Mi, line 10301031)

"Most of what I learned in university when teaching in high school, I ignored it all. I couldn't apply it." (Phong, line 1158-1159)

Thanh, Nam, and Phong shared the view that to some extent they could not make use of the methods of teaching which they were taught at school. Mi argued that the problem was not because of the methods themselves but the students' level was low.

Challenges in lesson preparation: Lesson preparation in the first years seemed to be quite demanding in the cases of Nam and Phong.

“... The work of preparing lessons for the first years of teaching is very heavy and very difficult... " (Nam, line 667-668)

“The lessons I composed are still simple." (Phong, line 1414)

After graduation, the novices had a chance to practice in a real teaching context. The first step is to plan the lessons. While Nam found preparing lessons challenging, Phong thought that his lessons were not good enough.

\section{Learners and Classroom Management Challenges}

Challenges in students' negative attitude towards learning English: Another challenge faced by three of four novices was students' negative attitude towards learning English.

“...It is ok that I don't understand, but as long as I get good grades, I just want good grades..." (Thanh, 145-146) [Thanh repeats what the students tell her. "I" means the students]

"...in the countryside, students have a view that...No! English is not an important subject. English is an unnecessary subject!"(Nam, line 675-676)

“...Students have no desire to learn. They don't try." (Mi, line 1043-1044)

Phong was the only novice working at a school for the gifted took part in the interview. Surprisingly, he also faced the problem of students' attitudes.

Those who intend to study abroad, don't pay attention to studying other subjects at the moment, because at the end of this year they are gone. Therefore, they don't care about grades anymore. As a result, it's very difficult for me to teach them. (Phong, line 1434-1436)

In Phong's case, when grades were no longer important to some students, who would study abroad in the coming time, they became distracted with their studies, including English. In other contexts such as urban areas in Mi's case or rural areas in Thanh and Nam's case, students did not have positive attitudes towards learning English either.

Challenges in students' proficiency: Thanh and Mi agreed that the students' level was low. For instance, they said

"I speak [English] but students don't understand, what should I do? The only way is to use Vietnamese."

(Thanh, line 263-264)

“...The students' level is low, I only teach grammar to them.” (Mi, line 1018)

Thanh claimed that because of the student's low proficiency, she must use Vietnamese instead of English to deliver the lessons. Facing the same problems, Mi had only one choice that was focusing on grammar instead of 
DOI: $\underline{10.51386 / 25815946 / \mathrm{ijsms}-\mathrm{v} 4 \mathrm{i} 5 \mathrm{p} 109}$

Volume: 4 Issue: 5

September to October 2021

https://www.ijsmsjournal.org

the four skills. The other participant, Nam, however, believed that the students were not weak, but they did not recognize the importance of the English subject. As teachers, we should explain and motivate them (Nam, line 681-686). By changing students' attitudes, Nam believed that they could excel in English.

School Context Challenges

Workload: Half of the participants said that the load of paperwork was too heavy.

"There are a lot of external things such as reports, then this and that, cluttered." (Thanh, line 149-150)

“...there are too many types of documents." (Nam, line 668)

When asked about the challenges, Thanh and Nam shared that they had to do a lot of paperwork, namely reports or academic records in paper form. It cannot be denied that besides teaching, the other workloads really caused unpleasantness to novice teachers.

Another Job Challenge

The pressure of achievement/ Credit-driven practice: Three of four teachers were under the pressure of achievement or credit-driven practice at school.

"...I'm more in that direction, which means I'm more negative, I see... I get credit-driven practice..." (Thanh, line 115-116)

"Interviewer: In addition to the difficulties you shared, have you experienced any other difficulties since entering high school until now?

Mi: Pressure of achievement." (Mi, line 1055-1057)

“... Currently, there is still credit-driven practice in school.” (Phong, line 1417)

The pressure of achievement or credit-driven practice is a hot issue of education which was mentioned again in this study. In those cases, if the novices do not follow the school's culture on this issue, they could be asked questions or scolded by the mentor teachers or school administrators.

\section{DISCUSSION AND CONCLUSION}

This study was conducted in order to explore the job challenges that novice EFL high school teachers in the Mekong Delta of Vietnam have to face. The main research question was "What job challenges do novice EFL high school teachers face in their first five years teaching in high schools?".

From the quantitative data, it was found that the participating novices faced various job challenges at a medium level of frequency in their career. Specifically, based on the results of three One-Sample T Tests, it can be concluded that the novices were confronted with school context challenges at a high level, followed by the medium level of learners and classroom management challenges. Finally, novices just deal with lesson-related challenges at a low level.

In addition, the findings from the semi-structured interviews presented several different job challenges divided into terms of lesson-related challenges, learners and classroom management challenges, and school context challenges. Specifically, the challenges synthesized by the semi-structured interviews included applying the teaching methods learned at university, lesson preparation, students' negative attitudes towards learning English, students' proficiency, workload, and pressure of achievement or credit-driven practice.

The findings are supported by the results of previous studies as presented below.

\section{Lesson-related Challenges}

Applying the teaching methods learned at university: This challenge was supported by various scholars namely Korukçu (1996), Alhamad (2018) and Sali and Kecik (2018). Korukçu (1996) indicated that teaching methodologies belonged to one of the most troublesome areas for pre-service and beginning EFL teachers. Alhamad (2018) added that the adoption of different educational techniques was also a noticeable challenge. Sali and Kecik (2018) also claimed that putting theory into practice was a problem in foreign language teaching and learning. This challenge could be explained that when novices practiced teaching in real contexts, they encountered a big problem which was students' low English proficiency. Because of this reason, novices could not apply the ideal teaching methods they learned at university. In this study, students' proficiency was also found as a type of challenge faced by Vietnamese novice EFL high school teachers. It can be seen that these two kinds of challenges have a close relationship.

Lesson preparation: The troublesome issue of lesson designing was also stated in related studies (Korukçu, 1996; Widiati et al., 2018; Sali \& Kecik, 2018; and Belatrech, 2018). The novices had to design the lessons to suit students' level, interests, and fit time allocation of the subject. Lesson preparation is considered as a 
DOI: $\underline{10.51386 / 25815946 / \mathrm{ijsms}-\mathrm{v} 4 \mathrm{i} 5 \mathrm{p} 109}$

Volume: 4 Issue: 5

September to October 2021

https://www.ijsmsjournal.org

challenging task for novices who have just entered the teaching career without much experience in designing the lessons.

Teaching at mixed-level classes: The finding that novice teachers had difficulties in teaching at mixed-level classes is in line with the previous studies (Alhamad, 2018; Sali \& Kecik, 2018). Novice teachers found that addressing individual learner differences was a challenging task. In addition, Belatrech (2018) claimed that adapting lessons to suit pupils' levels is another type of job challenge.

\section{Learners and Classroom Management Challenges}

Students' negative attitudes towards learning English: Alhamad (2018), and Lomi and Mbato (2020) pointed out that students have unfavorable attitudes towards learning English. In the Vietnamese context, English is a foreign language. As a result, apart from the study time in class, students do not have the needs or environments to use English. Therefore, students, especially those who live in the countryside acknowledge that English is an unnecessary subject, so they do not invest time and effort in it. This could explain students' negative attitudes towards learning English. To handle this problem, students should realize the importance of this subject so that they have a positive attitude towards it. Furthermore, ELF teachers, the school, and student's families should join hands to raise students' awareness and interest in this subject.

Students' motivation and interest: Several researchers have emphasized the lack of students' motivation and interest as factors that caused difficulties to novice teachers (Korukçu, 1996; Akcan, 2016; Sali \& Kecik, 2018; Widiati et al., 2018).

Students' proficiency: The challenges faced when teaching low English proficiency learners were also presented by many scholars (Akcan, 2016; Alhamad, 2018; Sali \& Kecik, 2018; Lomi \& Mbato, 2020). Learners' low English proficiency could result from another challenge named pressure of achievement or creditdriven practice. Although some students were not proficient enough to meet the subject's requirements, they were still approved to pass the subject. As a result, when those students studied in a higher grade, there was a big gap in their knowledge, which led to challenges for novices in teaching them. One more explanation for the challenge of students' proficiency was the time limitation for English subject. A large amount of knowledge conveyed in a limited time can make it difficult for students to absorb.

\section{School Context Challenges}

Workload: The area of workload was not mentioned much in the related studies on novice EFL teachers. Sali and Kecik (2018) stated that severe teaching burdens were a type of job difficulties related to school context challenges. In addition, in one study of novice ESL teachers, Richards and Pennington (1998) found that the heavy workload of teaching and non-teaching issues was one of the main challenges faced by novice ESL teachers at secondary schools in Hong Kong. In this current study, EFL high school teachers including the novices have numerous responsibilities. Besides the main responsibility of teaching, they also ought to carry out various other responsibilities namely managing students in educational activities organized by the school, coordinating with Ho Chi Minh Communist Youth Union to organize educational activities, being homeroom teachers, and doing administrative work. Carrying all those tasks could be overloaded to novice teachers.

School facilities and teaching resources: This finding is supported by Sali and Kecik (2018), Mahmud (2020), and Lomi and Mbato (2020). Sali and Kecik (2018) and Mahmud (2020) claimed that language teaching resources were inadequate. Lomi and Mbato (2020) added that necessary school facilities were also still lacking.

Large class sizes: The finding of teaching in large class sizes challenges is also consistent with the finding in studies of several scholars (Sali \& Kecik, 2018; Widiati et al., 2018).

\section{Another Job Challenge}

The pressure of achievement or credit-driven practice: Mahmud (2020) stated that the learning environment centered on testing was considered one of the major problems for teachers. When testing is highly valued, teachers in general and novices in particular have to deal with the pressure of achievement or credit-driven practice. The issue's source might not be from the novices themselves, but other individuals namely the presidents, the mentors, or students' parents. To save individuals' or schools' faces and reputations, they tend to create more pressure of student's scores on novice teachers.

The main results give insight into the common job challenges that novice EFL high school teachers encountered in their first five years of teaching practice. Thanks to those understandings, the stakeholders will 
DOI: $\underline{10.51386 / 25815946 / \mathrm{ijsms}-\mathrm{v} 4 \mathrm{i} 5 \mathrm{p} 109}$

Volume: 4 Issue: 5

September to October 2021

https://www.ijsmsjournal.org

have more understanding of the researched content and have plans to appropriately approach it. Several implications can be drawn in light of the mentioned findings.

First, pre-service education students should be provided with applicable teaching methods or approaches instead of being exposed to numerous methods in the undergraduate program that they might not be able to use in the real teaching context later.

Regarding lesson preparation, it is recommended that pre-service education students should have more opportunities to practice planning the lessons, even for the high grades like K11 or K12 in their learning program since it is possible that after graduation they may be in charge of these grades immediately. This is one of the practical tasks that is quite challenging but significant for teachers at the beginning phase of their career.

Additionally, it is necessary to change students' negative attitudes about learning English. The importance and practical significance of this subject should be widely disseminated to students. As a result, students' inner motivation would be nurtured and they could learn English more actively and efficiently.

Furthermore, students in each grade must be properly taught and assessed, so that when they reach a higher level, they can absorb the amount of knowledge designed for that level. What is more, the students having the same level of English proficiency should be placed in the same class. The number of students in English classes also needs to be reduced to ensure the effectiveness of teaching and learning.

Last but not least, information technology should be applied to reduce teachers' workload. Moreover, schools should be equipped with enough facilities and teaching resources to serve the need of learning and teaching the English subject.

Although the research aims of this current study were achieved, it still has a few limitations. First of all, only thirty novices answered the questionnaire and four were involved in the semi-structured interview. The sample size was considered as not big enough to generalize the results of the study. For this weakness, it was explained that finding and inviting novice EFL high school teachers working in the Mekong Delta to take part in the study was super challenging. For many years in a row, some provinces did not recruit EFL high school teachers. This leads to a scarcity of participants to invite to participate in the study. Besides, semi-structured interviews with novice teachers were conducted online which could affect the study's validation since the researchers did not meet the four participants in person.

Future studies on novice EFL high school teachers' job challenges should be done in a larger scope and employ multiple research methods to collect the data.

\section{ABOUT THE AUTHOR}

Ngoc Duyen Tran is currently a master student at Can Tho University, Vietnam. She completed a Bachelor's degree in English in Education in 2017. Her research interests include teaching methodologies, teachers' identities, and teachers' and students' challenges.

\section{REFERENCES}

[1] Akcan, S. (2016). Novice non-native English teachers' reflections on their teacher education programmes and their first years of teaching. Profile Issues in TeachersProfessional Development, 18(1), 55-70.

[2] Alhamad, R. (2018). Challenges and induction needs of novice English as a foreign language teachers in Saudi Arabia. International Journal of Education and Literacy Studies, 6(1), 50-63.

[3] Belatrech, H. S. K. (2018). Novice EFL teachers' challenges in Mostaganem rural areas. Social Sciences, 7(3), $125-132$.

[4] Bryman, A. (2008). Social research methods (3rd ed.). Oxford: Oxford University Press.

[5] Fantilli, R. D., \& McDougall, D. E. (2009). A study of novice teachers: Challenges and supports in the first years. Teaching and teacher education, 25(6), 814-825.

[6] Farrell, T. S. (2012). Novice-service language teacher development: Bridging the gap between preservice and in-service education and development. Tesol Quarterly, 46(3), 435-449.

[7] Hong, J. Y. (2010). Pre-service and beginning teachers' professional identity and its relation to dropping out of the profession. Teaching and teacher Education, 26(8), 1530-1543. 


\section{DOI: $\underline{10.51386 / 25815946 / i j s m s-v 4 i 5 p 109}$}

Volume: 4 Issue: 5

September to October 2021

https://www.ijsmsjournal.org

[8] Korukcu, S. (1996). An analysis of the problems of beginning teachers to develop an induction program for the Basic English departments of Turkish Universities (Doctoral dissertation, Bilkent University).

[9] Lomi, A. N. K., \& Mbato, C. L. (2020). Struggles and strategies in constructing professional identity: The first-year teaching experiences of Indonesian EFL novice teachers. Journal of English Education and Teaching, 4(1), 1-19.

[10] Mahmud, Y. S. (2020). INVESTIGATING EARLY-CAREER TEACHERS' ADAPTATION CHALLENGES: A CASE OF INDONESIAN EFL TEACHERS. PROJECT (Professional Journal of English Education), 3(3), 367-378.

[11] Öztürk, M. (2008). Induction into teaching: Adaptation challenges of novice teachers (Master's thesis, Middle East Technical University).

[12] Öztürk, M., \& Yildirim, A. (2013). Adaptation challenges of novice teachers. Hacettepe Üniversitesi Eğitim Fakültesi Dergisi, 28(281), 294-307.

[13] Pitton, D. E. (2006). Mentoring novice teachers: Fostering a dialogue process. Corwin Press.

[14] Richards, J. C. (1998). Beyond training: Perspectives on language teacher education. Cambridge University Press.

[15] Sali, P., \& Kecik, I. (2018). Challenges of First Years of Teaching in Turkey: Voices of Novice EFL Teachers. English Language Teaching, 11(4), 117-131.

[16] Senom, F., Zakaria, A. R., \& Ahmad Shah, S. S. (2013). Novice teachers' challenges and survival: Where do Malaysian ESL teachers stand?. American Journal of Educational Research, 1(4), 119-125.

[17] Tashakkori, A., \& Teddlie, C. (1998). Mixed methodology: Combining qualitative and quantitative approaches. Applied Social Research Methods Series (Vol. 46). Thousand Oaks, CA: Sage.

[18] Villegas-Reimers, E. (2003). Teacher professional development: an international review of the literature. Paris: International Institute for Educational Planning.

[19] Widiati, U., Suryati, N., \& Hayati, N. (2018). Unraveling the challenges of Indonesian novice teachers of English. Indonesian Journal of Applied Linguistics, 7(3), 621-629.

[20] Yost, D. S. (2006). Reflection and self-efficacy: Enhancing the retention of qualified teachers from a teacher education perspective. Teacher Education Quarterly, 33(4), 59-76. 